vulcanology I can give some of my experiences. In the first place it means a very big slice of time to read (for without this the thing had better be left alone) and review the annual litera. ture of such subjects; for this there is no recompense whatever, but as I shall show actual money out of pocket. It is impossible for the reviewer, unless residing in such towns a: London, Paris, or Berlin, to see all the literature of his subject. He, therefore, has to send out circulars, the expenses and postage of which, without counting labour of addressing, I found to come to about $2 l$. annually. A considerable proportion of these circulars are not even answered by those who have published papers on the subject during the year, and I am sorry to say that in one or two cases I have had a reply insinuating that I had been "cadging" for a copy of the author's paper or book. After the review is published come protests from authors (not many in my case, fortunately,) whom, out of common courtesy, time and money must be spent in answering. Finally, with every care such a work is far from complete. I would, therefore, hazard the following propositions:-A preliminary committee to be formed as soon as possible to study the question of international records of scientific literature. That such committee should determine the language of such records, the methods of organization of each separate subject committee, the means and resources of such, and invite the co-operation of other nations.

To my mind each record committee-say, for example, that of geology-should invite the specialists who are willing to collaborate to do so, should examine their manuscripts bef sre going to print, keep a list of all known workers in that particular branch, and find as many subscribers to the work as possible. The central committee should $n$ sminate the subject committees, treat with governments, societies, and universities for support, and keep a loose card catalogue of all scientific investigators in the world, to whom should be posted annually a circular requesting the dispatch of their publications, if $p$ ssible with a short abstract by themselves, to the reviewer of their special subject, the names and addresses of whom should be appended to the circular. In this way reduplication of reviewers circulars would not take place ; and if a botanist wrote a pxper on an earthq aake, for example, he would be reached by the application from the vulcanologist as well as by the botanis:. Finally, should profits accrue in the future, I would suggest that they be equally divided annually amongst the reviewers. really hope that the subject will be taken by the horns before we reach-and we are near-a great scientific literary deadlosk.

Harrogate, August 30. H. J. JoHNSTON-LAvis.

\section{A Suggestion for the Indexing of Zoological Literature.}

IT is obvious that the numerous records of all sorts which comprise the zoological literature of each year are only of use so far as we have access to and knowledge of them, and that their existence is actually a very serious encumbrance to those workers who are unable to make use of them.

It is self-evident that sooner or later, if zoology is to be preserved from chaos, every fact of any importance will have to be indexed for reference. Otherwise, nearly the whole lives of zoologists will come to be spent in libraries, until the thing gets so intolerable that some one suggests that we burn all the books, and start afresh from nature.

Of course, a great deal of indexing has been done, and is being done. The "Index Gen. et Spec. Anim." is well on the way, and the "Zoological Record" and other works of a like nature appear annually. But these are mainly records of names of species and genera described as new, and the "Zoological Record," admirable and invaluable as it is, is not always complete, nor in some sections (notably the last on mollusca) entirely accurate. Much indexing is continually being done in monographs, such as the Brit. Mus. Catalogues, and the value of this work can hardly be over-estimated, but here again it mostly relates to species as such. Then there is the Royal Society's "Catalogue of Scientific Papers," which is good so far as it goes, and the still more perfect Engelmann and Taschenberg. Putting aside, for the present, the question of indexing past records, would it not be a great advantage if we could begin now, and index everything as it appears? Possibly this could be done on the following plan :-

Let a society be formed, called, say, the Zoological Index Society, consisting of all writers on zoological subjects who will join.

NO. I I 93 , VOL. 46$]$
The members of the society to be provided with uniform record slips at cost price, on which they will undertake to record everything in their writings that they believe to be important or new. These records might be under various heads, e.g., the "semi-melanoid variety" of the leopard, described to the Zoological Society on November 20, 1883 , might be indexed under Felis pardus, under Melanism, and under Cape Colony.

These slips to be sent to the secretary of the society, who would arrange them in alphabetical order, in cabinets provided for the purpose. The slips, under each special heading (e.g., Species, Higher Groups, Variation, Distribution, \&c.) would form continuous series. The slips of each year might be kept separate for six months, and then merged in the general index.

The members would be required to pay a subscription sufficient to cover the expenses of the above; but it would probably be possible to obtain assistance from some of the scientific societies, and the most suitable place for the index to be kept is doubtless the Natural History Museum. If this were accomplished, it would still be cesirable to raise further funds, in order to increase the utility of the index in the following ways :-

(x) By obtaining an assistant secretary, whose duty it would be to copy out records from the index for workers residing in the country or abroad, at a certain small charge. The applicant might ask, e.g., for Limax, or Jamaica, or Albinism, and would pay according to the number of records.

(2) By publications. Possibly some arrangement might be made with the Zoological Record Committee, and special publications containing the records relating to matters then of interest might appear as often as possible.

Volunteer work in indexing earlier works would be acceptable. Thus, some admirer of Darwin might be willing to index the works of that author. But in such cases a careful list should be kept of the books indexed, and every index should be complete. Presumably no one will dispute the utility of an index as proposed, but some may doubt the possibility of getting sufficient co-operation. If the idea of such an idex became familiar to writers, it can hardly be doubted that each would desire to place his writings on record along with the rest. If a man's writings are not worth this trouble, they are surely not worth printing, unless, of course, they are of such a nature (e.g., educational works) as not to require indexing in this manner. T. D. A. Cockereli.

Institute of Jamaica, Kingston, Jamaica, August 15.

Rain with a High Barometer.

IN NATURE of September $\mathbf{I}$ in your note on the Annual Report on the Royal Botanic Gardens, Trinidad, you emphasize the fact that at Trinidad it always rains with a high barometer.

This is a not uncommon phenomenon in other parts of the world. Last year I made a series of meteorological observations in Mashonaland, and more especially while stopping during June and July at Zimbabwe, and I there found that a high barometer was invariably accompanied by rain, and the higher the barometer the more certain and heavy was the rain. The atmosphere was driest when the barometer was lowest, and then the difference of the reading 5 of the dry and wet bulb thermometers sometimes exceeded $20^{\circ} \mathrm{F}$.

This state of climate in Mashonaland is I think mainly due to the configuration of the country, which is such that moisture can only be carried there by southerly and south-easterly winds, and they-as winds blowing towards the equator generally doincrease the atmospheric pressure.

It will be interesting to know if some such explanation will not account for the condition of things in Trinidad, and if any of your readers can tell of a similar state of climate elsewhere.

15, Walmer Crescent, Glasgow, September 3 . ROBERT M. W. SWAN.

\section{The Perseids.}

WiTh reference to the note, August 18 th, that no news of the Perseids had then come to hand, I fancy the shower must have been fairly bright this year. One of our scholars, C. E. Elcock, while crossing from Belfast on the 9 th, saw some bright meteors in ten minutes between 9 and 9.30, one lasting some time. Afterwards only occasional ones occurred.

Bootham, York, August 29.

\section{J. EDMUND ClaRK.}

